\title{
Modern Uyghur Prosody
}

\author{
Yunhong Hou ${ }^{1, \mathrm{a}}$ \\ ${ }^{1}$ Xinjiang University, Foreign Languages School, Urumqi 830046, Peoples R China. \\ a43604243@qq.com
}

Keywords: Uyghur, Prosody, IPA.

\begin{abstract}
Modern Uyghur is spoken primarily in the urban areas of the Xinjiang Uyghur Autonomous Region in the People's Republic of China, which is about 3000 kilometers to the north-west of Beijing. Existing studies on modern Uyghur have focused mainly on its vowel harmony and agglutination, with few studies examining the prosody. The aim of the present description is therefore to provide a systematic phonetic description of segmental and prosodic aspects of Modern Uyghur, with main focuses on the prosodic aspects.
\end{abstract}

\section{Introduction}

Modern Uyghur is an official language of the Region and widely used as a common language by other ethnic minorities here. It is spoken primarily in the urban areas of the Xinjiang Uyghur Autonomous Region in the People's Republic of China, which is about 3000 kilometers to the north-west of Beijing. Existing studies on modern Uyghur have focused mainly on its vowel harmony and agglutination, with few studies examining the prosodic aspects. The aim of the present description is therefore to provide a systematic phonetic description of segmental and prosodic aspects of Modern Uyghur, with main focus on the prosodic aspects.

Uyghur belongs to the Karluk branch of the Turkic language family, which also includes languages such as Uzbek. Like many other Turkic languages, Uyghur displays vowel harmony and agglutination, lacks noun classes or grammatical gender, and is a left-branching language with subject-object-verb word order. More distinctly Uyghur processes include, especially in northern dialects, vowel reduction and umlauting. In addition to influence of other Turkic languages, Uyghur has historically been influenced strongly by Persian and Arabic, and more recently by Mandarin Chinese and Russian.

The modified Arabic-derived writing system is the most common and the only standard in China, although other writing systems are used for auxiliary and historical purposes. Unlike most Arabic-derived scripts, the Uyghur Arabic alphabet has mandatory marking of all vowels due to modifications to the original Perso-Arabic script made in the 20th century. Two Latin and one Cyrillic alphabet are also used, though to a much lesser extent. The Arabic and Latin alphabets both have 32 characters. (Wikipedia, updated 21 October 2017, at 07:20)

From the aspect of speech synthesis, there is an emotional prosody generator for a Uyghur speech synthesis system that can re-synthesize the selected vocal emotion from neutral synthesized speech output and improve the naturalness by adopting rule-based prosody conversion techniques. We'll start from the vowels and consonants in Modern Uyghur.

\section{Vowels and consonants in Modern Uyghur}

\subsection{Vowels in Modern Uyghur}

Vowels, like all sounds except the pure tone of a tuning fork, have complex structures. (Peter Ladefoged ,2005) The vowels of the Uyghur language are, in alphabetical order (in the Latin script), $\langle\mathrm{a}\rangle,\langle\mathrm{e}\rangle,\langle\mathrm{e}\rangle,\langle\mathrm{i}\rangle,\langle\mathrm{o}\rangle,\langle\ddot{\mathrm{o}}\rangle,\langle\mathrm{u}\rangle,\langle\ddot{\mathrm{u}}\rangle$.

There are no diphthongs in Uyghur and when two vowels come together, which occurs in some loanwords, each vowel retains its individual sound. 
It has been argued, within a lexical phonology framework, that /e/ has a back counterpart $/ \gamma /$, and modern Uyghur lacks a clear differentiation between /i/ and /w/.

\begin{tabular}{|c|c|c|c|c|}
\hline & \multicolumn{2}{|c|}{ Front } & \multicolumn{2}{c|}{ Back } \\
\hline $\begin{array}{c}\text { Unrounde } \\
\text { d }\end{array}$ & Rounded & $\begin{array}{c}\text { Unrounde } \\
\text { d }\end{array}$ & Rounded \\
\hline Close & $\underline{\mathrm{I}} \underline{\underline{\mathrm{i}}}$ & $\underline{\mathrm{y}} \underline{\underline{\mathrm{y}}}$ & $(\underline{\mathrm{i}}),(\underline{\mathrm{u}})$ & $\underline{\mathrm{v}}, \underline{\mathrm{u}}$ \\
\hline Mid & $\underline{\mathrm{e}}$ & $\underline{\underline{\gamma}})$ & \\
\hline Open & $\underline{\varepsilon}, \underline{\mathrm{x}}$ & $\underline{\emptyset}$ & $\underline{\Lambda}, \underline{\mathrm{a}}$ & $\underline{\mathrm{o}}, \underline{\mathrm{j}}$ \\
\hline
\end{tabular}

Fig. 1. Front and back vowels in modern Uyghur

\subsection{Consonants}

The acoustic structure of consonants is usually more complicated than that of vowels. (Peter Ladefoged ,2005)Uyghur voiceless stops are aspirated word-initially and intervocalically. The pairs /p, b/, /t, d/, /k, g/, and /q, b/ alternate, with the voiced member devoicing in syllable-final position, except in word-initial syllables. This devoicing process is usually reflected in the official orthography, but an exception has been recently made for certain Perso-Arabic loans. Voiceless phonemes do not become voiced in standard Uyghur.

Loan phonemes have influenced Uyghur to various degrees. $/ \bar{đ} / /$ and $/ \chi /$ were borrowed from Arabic and have been nativized, while /3/ from Persian less so. /f/ only exists in very recent Russian and Chinese loans, since Perso-Arabic (and older Russian and Chinese) /f/ became Uyghur /p/. Perso-Arabic loans have also made the contrast between $/ \mathrm{k}, \mathrm{g} /$ and /q, b/ phonemic, as they occur as allophones in native words, the former set near front vowels and the latter near a back vowels. Some speakers of Uyghur distinguish /v/ from /w/ in Russian loans, but this is not represented in most orthographies. Other phonemes occur natively only in limited contexts, i.e. $/ \mathrm{h} / \mathrm{only}$ in few interjections, /d/, /g/, and / $/$ / rarely initially, and /z/ only morpheme-final. Therefore, the pairs /ț, đz/, / 5 , 3/, and /s, z/ do not alternate.

The phonemes /g/ and / $\mathrm{b} /$ anywhere in a suffix alternate as governed by vowel harmony, where /g / occurs with front vowels and $/ \mathrm{b} /$ with back ones. Devoicing of a suffix-initial consonant can occur only in the cases of $/ \mathrm{d} / \rightarrow[\mathrm{t}], / \mathrm{g} / \rightarrow[\mathrm{k}]$, and $/ \mathrm{b} / \rightarrow[\mathrm{q}]$

Fig. 2. Consonants in Modern Uyghur

\begin{tabular}{|c|c|c|c|c|c|c|}
\hline & Labial & Dental & $\begin{array}{l}\text { Post-alveola } \\
\text { r }\end{array}$ & Velar & Uvular & Glottal \\
\hline Nasal & $\underline{m}$ & $\mathrm{n}$ & & n & & \\
\hline Stop & $\underline{\mathrm{b}}$ & $\mathrm{t}$ & $\mathrm{t} \int \mathrm{d} 3$ & $\begin{array}{ll}\mathrm{k} & \underline{\mathrm{g}} \\
\end{array}$ & $\mathrm{q}$ & $\underline{?}$ \\
\hline Fricative & $\begin{array}{ll}\underline{f} & (\underline{v})\end{array}$ & $\underline{\mathrm{s}}$ & f 3 & & $\chi \underline{\underline{b}}$ & $\underline{\mathrm{h}}$ \\
\hline Trill & & $\underline{r}$ & & & & \\
\hline Approximant & & $\underline{l}$ & $\mathrm{j}$ & $\underline{\mathrm{w}}$ & & \\
\hline
\end{tabular}




\section{Prosody in Modern Uyghur}

These contribute to linguistic functions such as intonation, tone, stress, and rhythm,are of prosodic features of a language. In linguistics, Modern Uyghur prosody is concerned with those elements of Modern Uyghur speech that are not individual phonetic segments (vowels and consonants) but are properties of syllables and larger units of speech.Prosody may reflect various features of the speaker or the utterance: the emotional state of the speaker; the form of the utterance (statement, question, or command); the presence of irony or sarcasm; emphasis, contrast, and focus; or other elements of language that may not be encoded by grammar or by choice of vocabulary.

Fig. 3. Prosodic hierarchics in Modern Uyghur

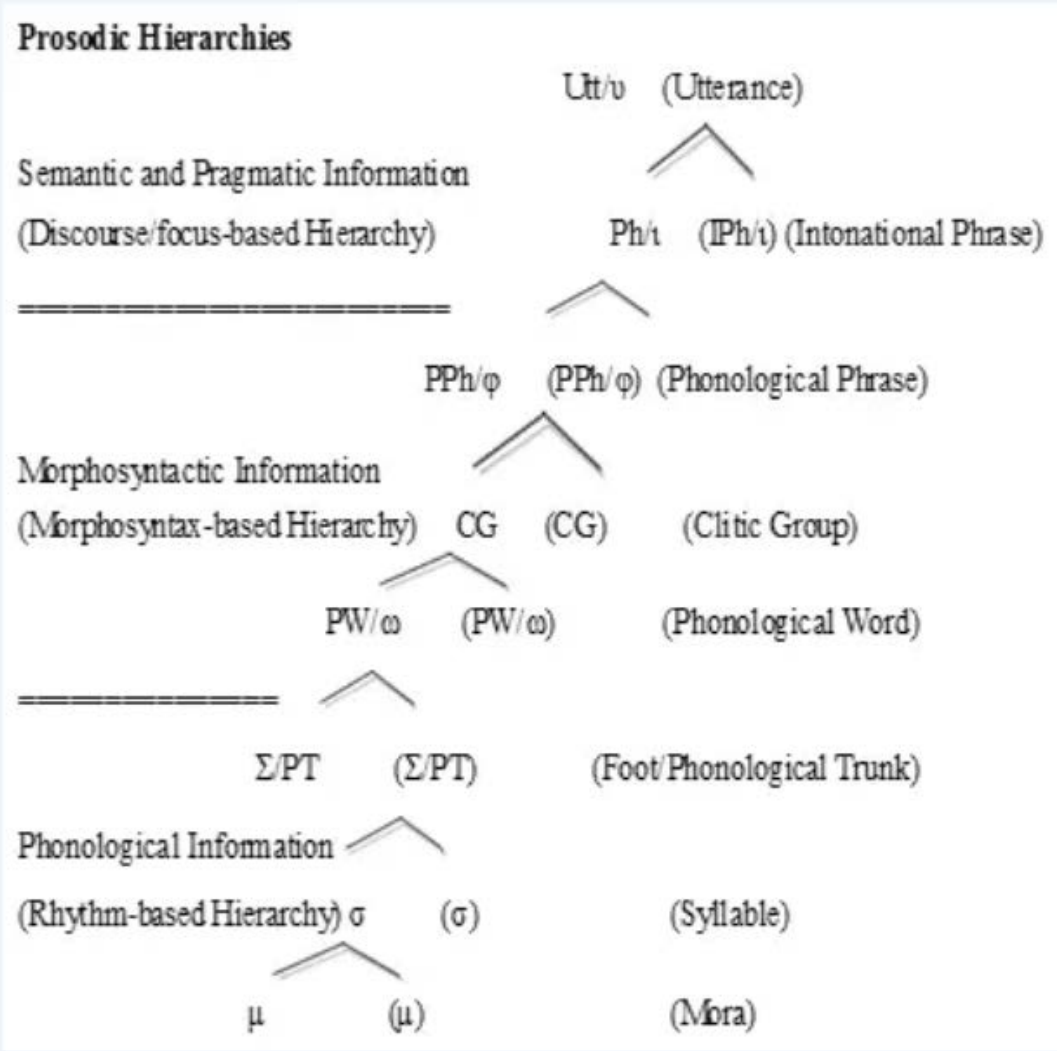

\section{Conclusion}

Different combinations of Modern Uyghur variables are exploited in the linguistic functions of intonation and stress, as well as other prosodic features such as rhythm, tempo and loudness. Additional prosodic variables have been studied, including voice quality and pausing.

\section{Acknowledgement}

In this paper, the research was sponsored by the Ministry of Education Social Science Youth Fund for Xinjiang Uygur Autonomous Region of China (Project No. 17XJJC740001).

\section{References}

[1] Prosody conversion from neutral speech to emotional speech. Jianhua Tao, Yongguo Kang,Aijun Li. IEEE Transactions on Audio, Speech, and Language Processing . 2006

[2] Prosody-Syntax Interaction in the Expression of Focus[J] . Vieri Samek-Lodovici. Natural Language \& Linguistic Theory . 2005 (3) 
[3] Keeping the Floor in Multiparty Conversations: Intonation, Syntax, and Pause[J] . Ann Wennerstrom,Andrew F. Siegel. Discourse Processes . 2003 (2)

[4] Prosody in skilled silent reading: evidence from eye movements[J] . JaneAshby. Journal of Research in Reading . 2006 (3)

[5] Vowels and Consonants. $2^{\text {nd }}$ ed. Peter Ladefoged. Oxford:Wiley-Blackwell,2005 